गा

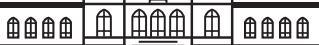

B E ZM I A L E M

VAKIF UNIVERS ITY
BEZMîÂEM Science

\title{
EDITORIAL
}

\section{Dear Readers;}

We are happy to be with you in the fourth issue of the year 2020. SARS-CoV-2 makes us live the second peak period in our country and in European countries. Daily life continues to involve many challenges, especially for health workers. Despite our "new normal" efforts, we have difficulty implementing them. However, together with our esteemed readers, we strive to improve everything for the better, and we also get good results during this difficult period. I said in our last issue that we would publish a special issue about COVID-19, and I noted that we received around 40 valuable articles. After all, articles about this topic still continue to arrive. From now on, we will accept these articles in our normal issues. Due to the abundance of articles, we will publish our special issue in possible 3 chapters. Despite the difficulties, we solved many problems with the excellent efforts of our editorial board and decided to publish the first two chapters consecutively with this issue.

Our issue continues to make breakthrough. We are happy to share valuable works with you, our precious readers, in the last issue of the year 2020. As a result of the studies carried out in order to achieve better positions and increase accessibility of our journal, I would like to inform you, our precious readers, that our journal has entered index databases called CABI (our content from our publications in 2019 will be seen in the CABI database), Gale and Index Copernicus.

I would like to mention our cover art and selected articles in this issue;

We are very happy to be together once again with beautiful topics in this issue. "A Radiographic Comparison of the Root Length and Area After Class II Treatment with Two Different Functional Appliances" by Şeker et al., "Evaluation of Nosocomial Infections and Antimicrobial Resistance Profiles in the Intensive Care Units: Nine Years Experience" by Keskin Seremet et al., "Gastroschisis Treatment: Evaluation of Surgical Techniques and Results" by Ince et al., and "The Impact of Moral Sensitivities and Professional Values of Nursing Students on Care Perception" by Lafci et al. are the articles on the forefront in this issue.

We will be with you with innovations in the year 2021. From this year on, we will develop our editorial section and create a separate section from selected topics. The selected guest and his/her article will be published with the editor's comment. We will accept your original articles in Turkish and English. We only want reviews to be sent in English. Original articles to be submitted in English will be published in a shorter time than others since they will not have a translation process.

I would like to thank all of our healthcare professionals who work devotedly at the expense of their lives during these difficult days due to the COVID-19 pandemic. I wish God's mercy to the healthcare professionals who lost their lives in this struggle, my condolences to their families and patience.

I would like to thank our publishing house, our editorial board and our reviewers for taking their time and preventing interruptions despite the increasing workload.

I wish you all the best and hope to see you in our next issue in the new year...

Yours truly

\section{Prof. Dr. Adem AKÇAKAYA}

Editor-In-Chief 